\title{
AGE, CLIMATE AND INTRA-ANNUAL DENSITY FLUCTUATIONS IN PINUS HALEPENSIS IN SPAIN
}

\author{
Klemen Novak ${ }^{1,2,3, *}$, Miguel Angel Saz Sánchez ${ }^{1}$, Katarina Čufar ${ }^{2}$, \\ Josep Raventós ${ }^{3}$ and Martin de Luis ${ }^{1}$ \\ 1University of Zaragoza, Department of Geography and Regional Planning, C/Pedro Cerbuna 12, \\ 50009 Zaragoza, Spain \\ ${ }^{2}$ University of Ljubljana, Biotechnical Faculty, Department of Wood Science and Technology, \\ Rožna dolina, Cesta VIII/34, 1000 Ljubljana, Slovenia \\ ${ }^{3}$ University of Alicante, Department of Ecology, Carretera San Vicente del Raspeig s/n, \\ 03690 San Vicente del Raspeig-Alicante, Spain \\ *Corresponding author: e-mail: kn4@alu.ua.es
}

\begin{abstract}
Intra-annual density fluctuations (IADFs) in tree rings of Aleppo pine (Pinus halepensis) are considered to be among the most promising wood anatomical features in dendrochronological studies. They provide environmental information in addition to those obtained from tree-ring widths. We used a network of 35 sites in Spain, ranging from nearly desert to temperate climate. We analysed tree-ring series of 529 trees to study IADF frequencies, and their dependence on climatic factors and cambial age. The results showed that IADF frequency is age dependent, with its maximum at the cambial age of 27 years (evaluated at breast height). The frequencies varied across the network and at different sites we recorded that $0.3 \%$ to $33 \%$ of the analysed tree rings contained IADFs. They were more frequent where and when the temperatures were higher, summer drought was intense and autumn was the main precipitation season. IADF formation was particularly related to high minimum temperatures and wet conditions in late summer and autumn. These results suggest that IADF formation is not related to stressful conditions during summer but to favourable conditions during autumn. These conditions promote cambial reactivation and consequently formation of wider tree rings.
\end{abstract}

Keywords: Aleppo pine, wood structure, tree rings, Mediterranean.

\section{INTRODUCTION}

The Aleppo pine (Pinus halepensis Mill.) is an important and widespread tree species in the Mediterranean and can grow under widely diverse climatic conditions (Barbéro et al. 1998; Richardson \& Rundel 1998; De Micco et al. 2013) on a great variety of substrates and on poor soil. It is thermophilous and heliophilous, and tolerant to high temperatures and drought, but does not cope well with excessive humidity, frost and snow (Girard et al.2012). Due to its growth plasticity and adaptability to different site and climatic conditions, it is an important species to study the effect of climatic change 
on trees across the Mediterranean. In this area, the summer drought represents the main constraint for tree growth with great inter-annual variations in duration and intensity (Girard et al. 2012). Climatic models predict progressive warming and reduction of precipitation (Christensen et al. 2007) which are expected to endanger the survival of trees, especially at more extreme sites (Alcamo et al. 2007).

In this context, dendrochronology enables us to study past responses of trees to climate (Nicault et al.2008) and helps us to predict future vegetation shifts in response to climatic change. Pinus halepensis has a typical conifer wood structure, containing resin canals and clearly distinguishable tree rings with earlywood (EW) and latewood (LW), and more or less gradual transition between them (Schweingruber 1988). However, deviations from such normal structure are frequent and are characterised by abrupt changes in ring width, variable frequency of normal and of traumatic resin canals, and intra-annual density fluctuations (IADFs) (De Luis et al. 2007; Novak et al. 2011; Olivar et al. 2012).

The combined approach of dendrochronology and quantitative wood anatomy has been also used to characterise IADFs in dated tree rings. Tree rings containing IADFs can be in some cases divided into different types, like the ones with latewood-like tracheids within the earlywood (E-rings), or with earlywood-like tracheids within the latewood (L-ring) (Campelo et al. 2007a). A recent wood formation study in P. halepensis on an extremely dry site in Spain has shown that L-type IADFs are formed as a consequence of cambial reactivation in autumn after its stop or slowdown during hot and dry summers (De Luis et al. 2011b). However, another recent study in P. halepensis of various sites in Spain has demonstrated that L-rings are much more frequent than E-rings (Novak et al. 2013).

Dendrochronological studies of $P$. halepensis proved that IADFs provide valuable information of climate-growth relationship in addition to the information obtained from tree-ring widths (Novak et al. 2013). This is in agreement with other reports on the high importance of density, wood structural features, and cell dimensions in dendrochronology and ecological studies (Battipaglia et al. 2010, 2013; Fonti et al. 2010; MartinBenito et al.2013; Campelo et al.2013; Panayotov et al.2013). However, the information obtained from IADFs may greatly vary depending on site conditions, population structure and inter-annual as well as intra-annual variability in environmental conditions of the sites (Novak et al. 2013). As a consequence, our knowledge of the main climatic factors promoting IADFs across different environmental conditions is still deficient.

The main purpose of this study was to use a dense and diverse dendroclimatic network in Spain to establish the frequency variation of IADFs in P. halepensis, and to determine the climatic factors which promote IADF formation, as well as whether the processes are age dependent.

\section{MATERIAL AND METHODS}

\section{Sampling sites and climatic conditions}

The study was carried out in the Mediterranean area in Spain, at 35 different sites with different climatic conditions (Fig. 1; Table 1). Mean annual temperatures on the sites ranged from $10.9^{\circ} \mathrm{C}$ (the coldest site) to $18.3^{\circ} \mathrm{C}$ (the warmest site) and mean 


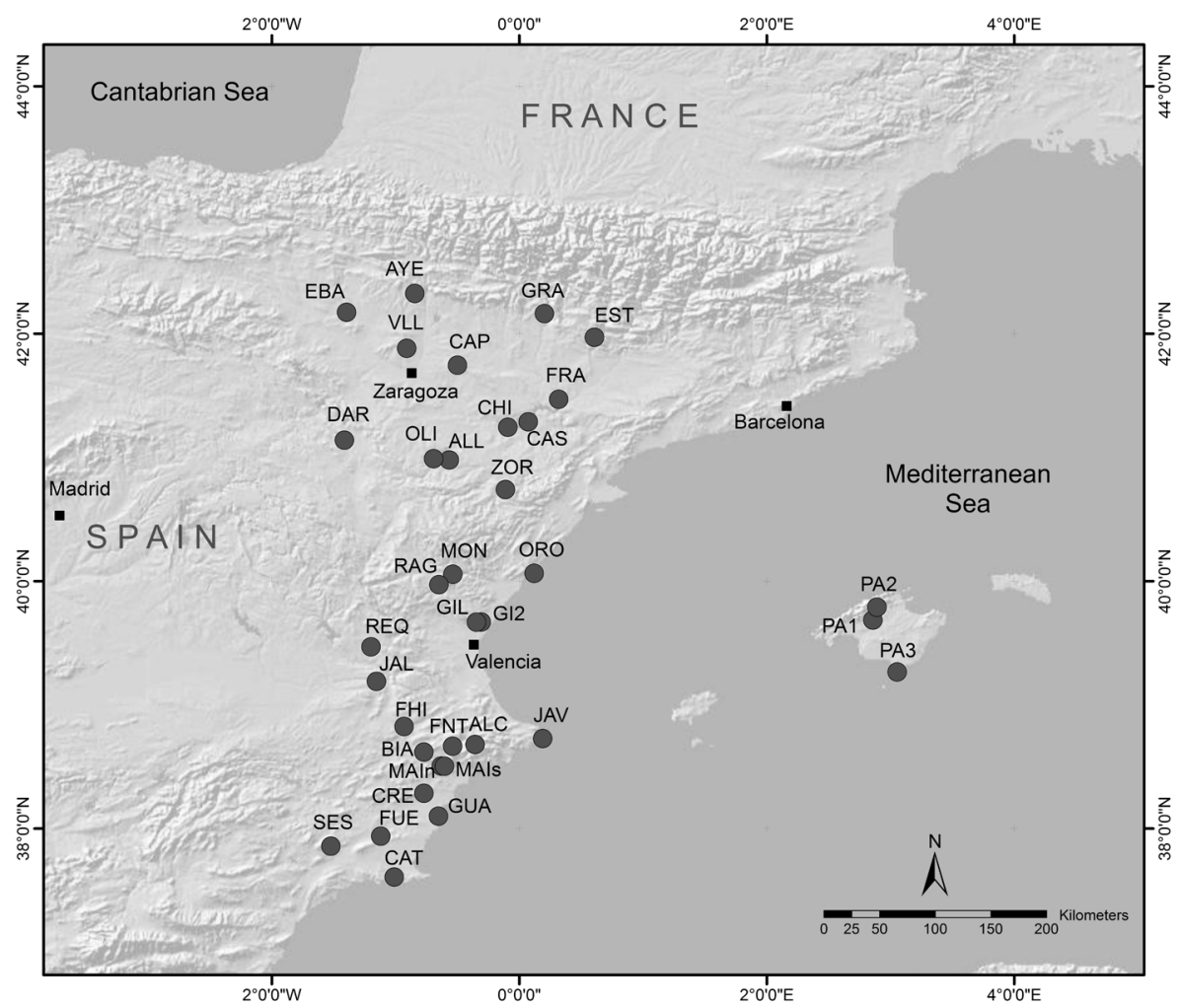

Figure 1.35 sampling sites of Pinus halepensis trees in the Mediterranean area in Spain.

annual precipitation from $243 \mathrm{~mm}$ (the driest site) to $1181 \mathrm{~mm}$ (the wettest site). The distribution of total precipitation is from 6 to $22 \%$ in summer and from 27 to $44 \%$ in autumn.

Sampling was conducted on mature, apparently healthy Aleppo pine (Pinus halepensis Mill.) trees, without any visible damage. We selected 9 to 33 trees per site and extracted 1 to 8 cores per tree at breast height, altogether 1054 samples from 529 trees in total were studied.

The cores were then labelled, fixed on wooden supports, air-dried and sanded with progressively finer grades of sandpaper $(80,180,300,500$ grit $)$ until the tree-ring structure was clearly visible under the stereo microscope.

\section{Tree-ring measurements and standardisation procedures}

The tree-ring series were visually and statistically crossdated and compared between each other by calculating the t-value after Baillie and Pilcher (1973) using the TSAPWin Scientific program (version 4.68e). Additionally the quality of crossdating was verified using the COFECHA program - version 6.06P (Holmes 1994).

The tree-ring widths (TRW) were measured under a stereo microscope with an accuracy of $0.01 \mathrm{~mm}$, with the TSAP-Win Scientific program and LINTABTM5 


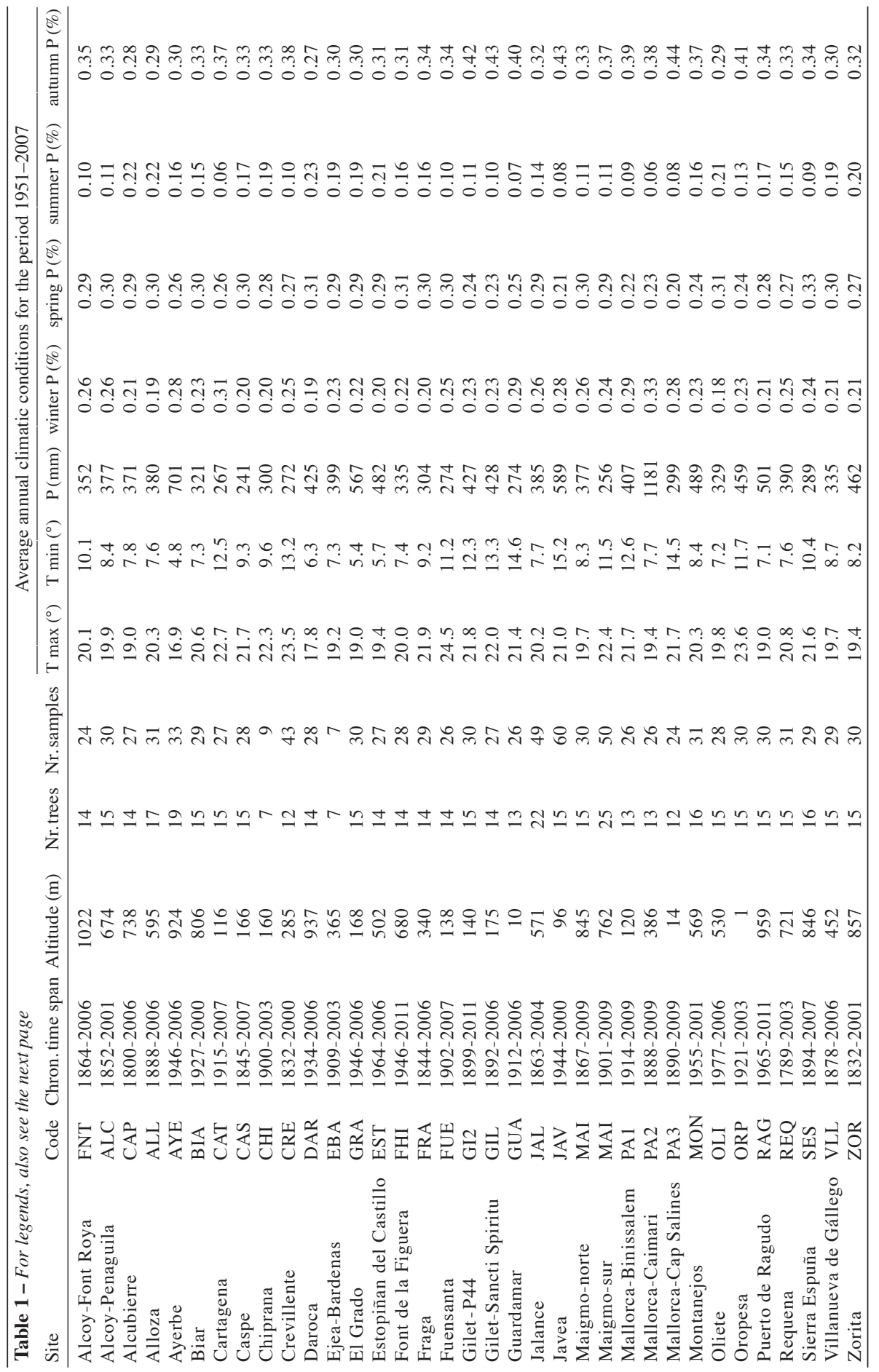


Table 1. Description of 35 sampling sites of Pinus halepensis trees in the Mediterranean area in Spain: site name and code, chronology time span, altitude, number of trees and samples, and average annual climatic conditions for the period 1951-2007: mean maximal annual temperatures $\left(\mathrm{T}_{\max }\right)$, mean minimal annual temperatures $\left(\mathrm{T}_{\min }\right)$, mean annual precipitation (P) and seasonal distribution of precipitation in winter (\% winter $\mathrm{P})$, spring (\% spring $\mathrm{P})$, summer (\% summer $\mathrm{P})$ and autumn (\% autumn $\mathrm{P})$.

measuring device (RINNTECH e.K., Hardtstrasse 20-22, D-69124 Heidelberg, Germany, www.rinntech.com).

Quantitative wood anatomy was used to characterise intra-annual density fluctuations (IADFs) in dated tree rings. We analysed 81,238 tree rings with a stereo microscope. Since in many cases it was not possible to objectively differentiate between different IADF types, we only classified their presence in the tree rings. We assigned the value 1 if the IADF was present in the individually dated tree rings, and the value 0 if it was not observed (Fig. 2). Only one person completed the classification, in order to obtain comparable results.

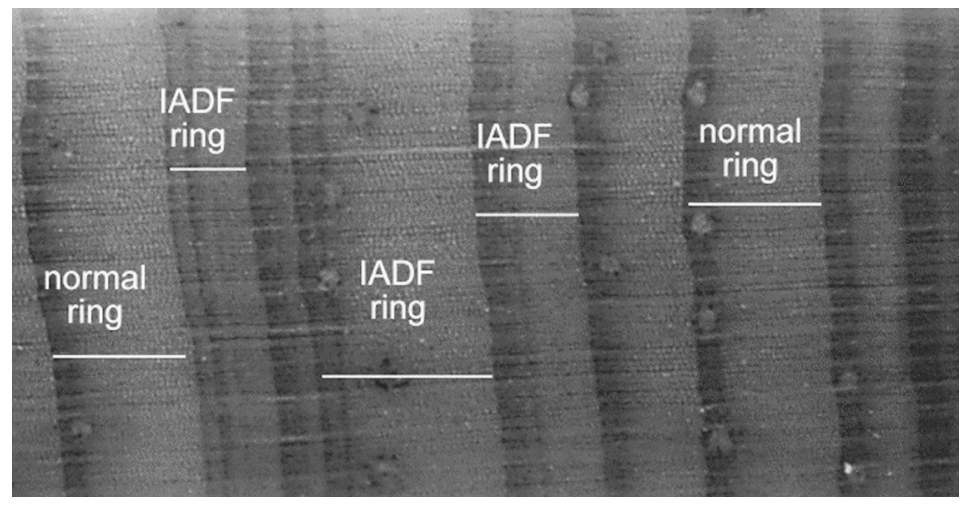

Figure 2. Tree rings of Pinus halepensis: normal rings, and rings showing intra-annual density fluctuations (IADFs).

Raw series of TRW and of IADF frequencies were calculated individually for each of the 529 analysed trees using the arithmetic mean of the available samples.

To study age-related growth trends, the raw series of IADF frequencies were aligned by biological cambial age observed at breast height considering pith-offset estimations, and averaged for each age using the arithmetic means. Then, a three-parameter Weibull function (Equation 1) was employed to explore the relationship between the cambial age and the average IADF frequency observed for each age.

$$
\operatorname{IADF}_{(f)}=a * b * c * A g e^{2 *} e^{-a * A g e^{b}}
$$

Equation 1

Where $\mathrm{IADF}_{(\mathrm{f})}$ is the observed frequency of tree-rings containing IADF, Age is the cambial age observed at breast height of the trees and $a, b$ and $c$ are fitting parameters. 
The resulting Weibull equation was later used as a regional curve for detrending purposes (Briffa et al. 1992; Esper et al. 2003). Thus, for each individual tree, the standardised frequency series of IADFs $\left(\operatorname{IADF}_{(\operatorname{Std} f)}\right)$ were calculated as the difference between the observed and the predicted $\operatorname{IADF}_{(\mathrm{f})}$.

The arithmetic means of $\left.\operatorname{IADF}_{(\mathrm{Std}} \mathrm{f}\right)$ series, which are age independent, were then calculated for each study site to describe spatial variations in the occurrence of IADFs across the network.

\section{The climate-IADF relationship}

Monthly values of total precipitation, average maximum and minimum temperature collected at each site in the period from 1950 to 2007 were obtained from Spain 02 database (Herrera et al. 2012).

The information from 27,430 tree rings for which the climatic data were available was used to identify the climatic conditions that promote and trigger the formation of IADFs.

For each analysed tree ring, we calculated different climatic parameters (maximal temperatures, minimal temperatures and total precipitation) for months between September of the previous year to November of the current year and for the climatic seasons: winter (December, January, February), spring (March, April, May), summer (June, July, August) and autumn (September, October, November). For each analysed climatic parameter we divided the observed range of values into the percentiles. Then, for each percentile class, we calculated the average of the standardised IADF frequencies $\left(\operatorname{IADF}_{(\mathrm{Std} f)}\right)$ as observed in individual tree rings. Pearson's Product Moment Correlation Coefficient was used to measure strength of association between the average of the $\operatorname{IADF}_{(\mathrm{Std} f)}$ and the average value of the percentile class.

\section{Differences in widths between the tree rings containing IADFs and those without IADF S}

For each set of site/year conditions, the ratio between the average ring width calculated for the tree rings containing IADFs and the average ring width calculated for tree rings without IADFs was computed. Then, for each study site, we applied a T-test between the obtained series of ratios in order to establish the differences in ring width between tree rings containing IADFs and tree rings without IADFs.

\section{RESULTS}

\section{Tree-ring network and effect of age on IADF frequency}

The established tree-ring network consists of 529 tree-ring series of Pinus halepensis from 35 sites in Spain. The average length of tree-ring series is 81 years, ranging from 24 to 215 years. Of the 81,238 analysed tree rings, 6,937 (8.54\%) showed IADFs. The frequency of IADFs varied with cambial age and reached its maximum of $10.5 \%$ at the cambial age at breast height of 27 years. With the three-parameter Weibull function we confirmed that IADF frequency depends on cambial age $\left(\mathrm{r}^{2}=0.874 ; \mathrm{p}<0.01\right)$ as shown in Figure 3. 


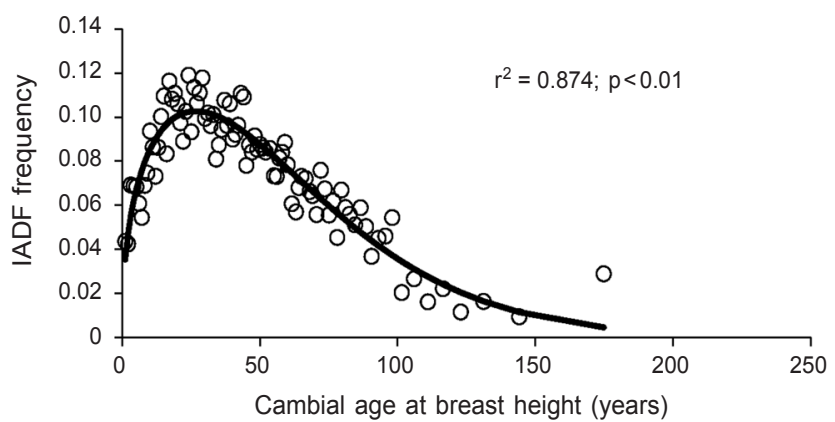

Figure 3. The effect of cambial age (horizontal axis) on IADF frequency (vertical axis) as explained with three-parameter Weibull function $\left(\mathrm{IADF}_{(\mathrm{f})}\right.$ is the observed frequency of treerings containing IADF, Age is the cambial age observed at the breast height of the trees and $a, b$ and $c$ are fitting parameters).

Table 2. Description of IADF frequency (raw frequency $\left(\operatorname{IADF}_{(\mathrm{f})}\right.$ and standardised frequency $\left.\operatorname{IADF}_{(\text {std f) }}\right)$ and ratio between tree-ring widths with IADF and tree-ring widths without IADF $\left(\mathrm{TRW}_{(\mathrm{IADF})} / \mathrm{TRW}_{(\mathrm{no} \text { IADF) }}\right.$, average and $\mathrm{p}$ value) at 35 sampling sites.

\begin{tabular}{|c|c|c|c|c|c|}
\hline \multirow[b]{2}{*}{ Site name } & \multirow[b]{2}{*}{ Code } & \multicolumn{2}{|c|}{ IADF frequency } & \multicolumn{2}{|c|}{$\mathrm{TRW}_{(\mathrm{IADF})} / \mathrm{TRW}_{(\mathrm{no} \mathrm{IADF})}$} \\
\hline & & $\operatorname{IADF}_{(f)}$ & $\operatorname{IADF}_{(\operatorname{std} f)}$ & Average & $\mathrm{p}$ value \\
\hline Alcoy-Penaguila & ALC & 0.0083 & -0.0544 & 1.3886 & 0.0247 \\
\hline Alcoy-Font Roja & FNT & 0.0386 & -0.0361 & 1.3331 & 0.0110 \\
\hline Alcubierre & CAP & 0.0119 & -0.0667 & 0.9927 & 0.9239 \\
\hline Alloza & ALL & 0.0363 & -0.0402 & 1.3762 & 0.0003 \\
\hline Ayerbe & AYE & 0.0228 & -0.0673 & 1.3822 & 0.0799 \\
\hline Biar & BIA & 0.1190 & 0.0306 & 1.0620 & 0.1243 \\
\hline Cartagena & CAT & 0.0788 & -0.0037 & 1.7765 & 0.0006 \\
\hline Caspe & CAS & 0.0091 & -0.0554 & 1.1860 & 0.3839 \\
\hline Chiprana & $\mathrm{CHI}$ & 0.0383 & -0.0394 & 1.6676 & 0.0014 \\
\hline Crevillente & CRE & 0.0574 & -0.0190 & 1.3933 & 0.0000 \\
\hline Daroca & DAR & 0.1751 & 0.0861 & 1.3268 & 0.0004 \\
\hline Ejea-Bardenas & EBA & 0.0210 & -0.0665 & 0.8796 & 0.2620 \\
\hline El Grado & GRA & 0.0033 & -0.0870 & 1.2032 & 0.3991 \\
\hline Estopiñan del Castillo & EST & 0.0601 & -0.0307 & 1.5839 & 0.0041 \\
\hline Font de la Figuera & FHI & 0.0870 & -0.0029 & 1.2073 & 0.0643 \\
\hline Fraga & FRA & 0.0164 & -0.0445 & 1.4410 & 0.0079 \\
\hline Fuensanta & FUE & 0.2526 & 0.1726 & 1.5799 & 0.0000 \\
\hline Gilet-Sancti Spiritu & GIL & 0.1600 & 0.0806 & 1.5725 & 0.0021 \\
\hline Gilet-P44 & GI2 & 0.1718 & 0.0920 & 1.6654 & 0.0000 \\
\hline Guardamar & GUA & 0.1580 & 0.0750 & 1.3544 & 0.0000 \\
\hline Jalance & JAL & 0.0591 & -0.0143 & 1.2350 & 0.0016 \\
\hline Javea & JAV & 0.3300 & 0.2422 & 1.3162 & 0.0000 \\
\hline Maigmo-norte & MAIn & 0.0494 & -0.0282 & 1.4956 & 0.0000 \\
\hline Maigmo-sur & MAIs & 0.0837 & 0.0029 & 1.0558 & 0.3179 \\
\hline Mallorca-Binissalem & PA1 & 0.1957 & 0.1163 & 1.7457 & 0.0000 \\
\hline Mallorca-Caimari & PA2 & 0.1580 & 0.0775 & 1.6831 & 0.0000 \\
\hline Mallorca-Cap Salines & PA3 & 0.0657 & -0.0069 & 1.8026 & 0.0001 \\
\hline Montanejos & MON & 0.0461 & -0.0446 & 0.9667 & 0.5743 \\
\hline Oliete & OLI & 0.1237 & 0.0328 & 1.0302 & 0.7076 \\
\hline Oropesa & ORO & 0.1635 & 0.0773 & 1.2853 & 0.0016 \\
\hline Puerto de Ragudo & RAG & 0.0598 & -0.0312 & 1.1799 & 0.0595 \\
\hline Requena & REQ & 0.0233 & -0.0312 & 1.6106 & 0.0000 \\
\hline Sierra Espuña & SES & 0.0812 & 0.0049 & 1.3456 & 0.0000 \\
\hline Villanueva de Gállego & VLL & 0.0165 & -0.0582 & 1.1062 & 0.3154 \\
\hline Zorita & ZOR & 0.0407 & -0.0309 & 1.2757 & 0.0026 \\
\hline
\end{tabular}




\section{Spatial variation in the frequency of IADFs}

The frequency of IADFs varies across the geographical distribution of Pinus halepensis in Spain (Fig. 4; Table 2). The lowest frequency of $0.3 \%\left(\operatorname{IADF}_{(\operatorname{Std} f)}=-0.09\right)$ was observed in Ayerbe, close to the Pyrenees, at an altitude of $924 \mathrm{~m}$; the highest frequency of $33 \%\left(\mathrm{IADF}_{(\mathrm{Std} f)}=0.24\right)$ was observed in Javea on the Mediterranean coast, at an altitude of $96 \mathrm{~m}$. The occurrence of IADFs is generally more frequent on the sites near the coast and on the Balearic Islands (Mallorca). IADFs are generally less frequent in the inland, in the mountains and especially on the northern part of the distribution range of $P$. halepensis.

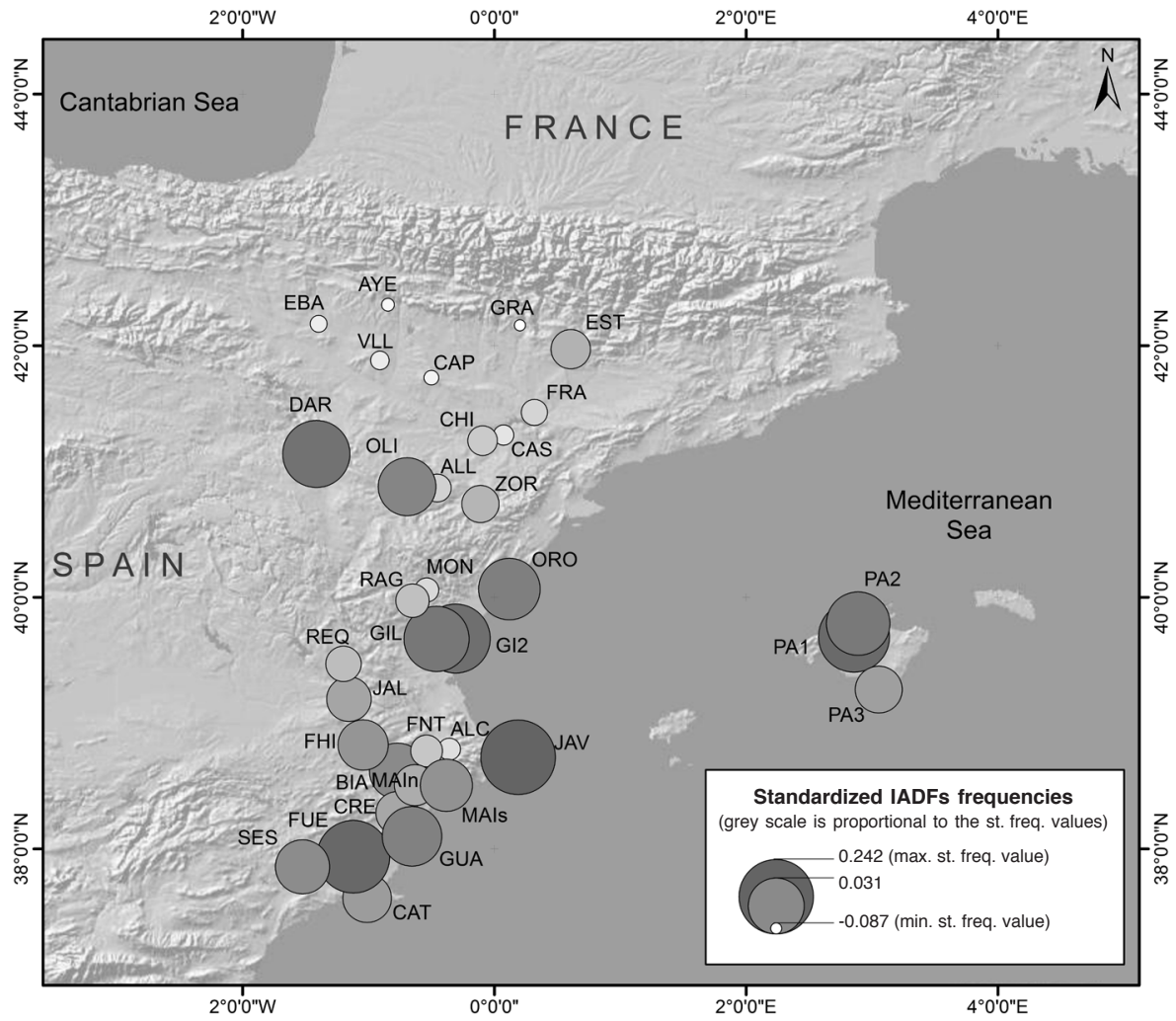

Figure 4. Spatial variation in the occurrence of standardized IADF frequencies, from the lowest (smallest point) of $0.3 \%$ (e.g. Ayerbe) to the highest frequency (largest point) with $33 \%$ (e.g. Javea).

\section{The climate $-I A D F$ relationship}

Analysis of spatio-temporal variations of IADFs showed that they are more frequent at the sites and in years with warm climatic conditions, especially in terms of minimal temperatures, and where/when autumn is the main precipitation season (Fig. 5 \& 6). Hot and dry summers were hypothesised to be the most prominent and stressful climatic element promoting IADF formation. Interestingly, the IADFs are not related to 


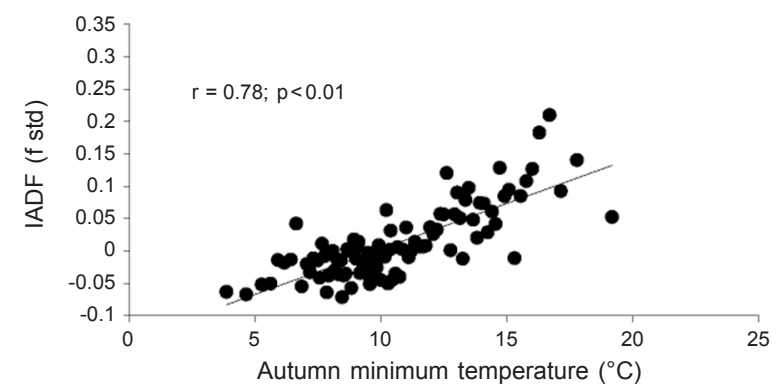

Figure 5. Increasing standardized IADF frequencies with increasing autumn minimum temperature. The correlations are significant.

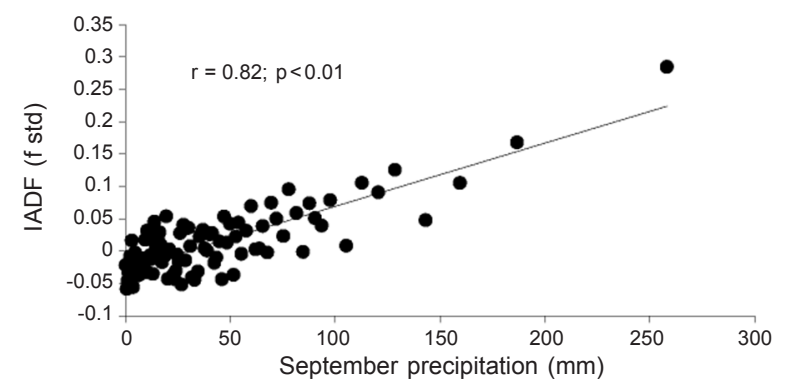

Figure 6. Increasing standardized IADF frequencies with increasing September precipitation. The correlations are significant.

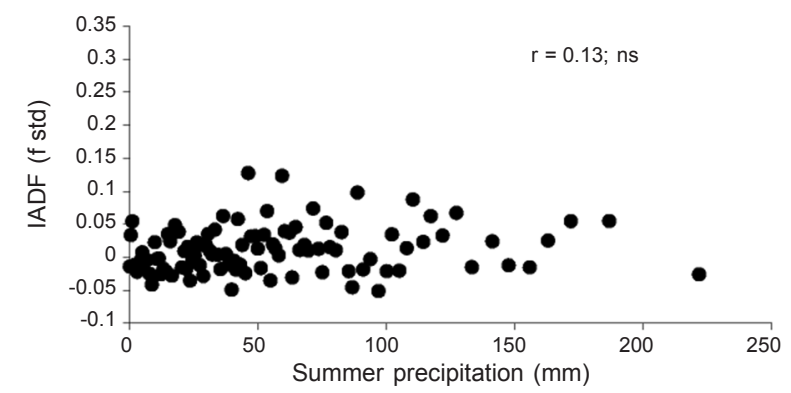

Figure 7. Standardized IADF frequencies and summer maximum temperature. The correlations are not significant.

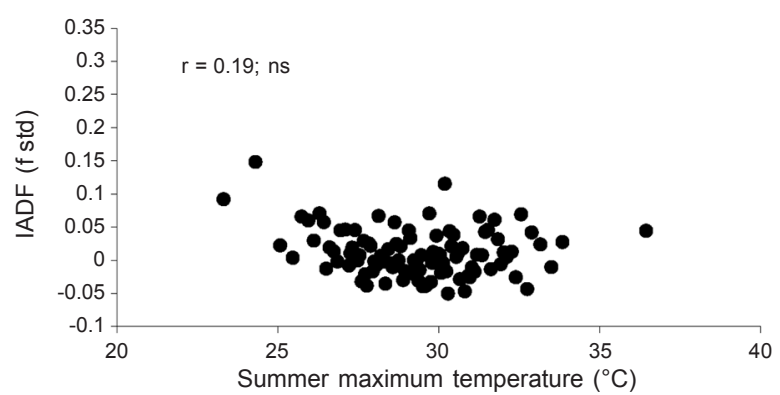

Figure 8. Standardized IADF frequencies and summer precipitation. The correlations are not significant. 
summer conditions in terms of maximal summer temperatures and total amount of precipitation (Fig. $7 \& 8$ ); they are strongly related to autumn conditions. Higher minimum temperatures and higher precipitation in autumn, especially in September have proved to be the most critical climatic elements promoting IADF formation. This suggests that favourable conditions for cambial production - which are probably related to its reactivation after summer drought - may trigger IADF formation.

\section{Differences between the widths of tree rings containing IADFs and the widths of tree rings without IADFs}

Generally, IADFs occur in wider tree rings; the tree rings containing IADFs are on average 1.42 times wider than those without IADFs (Table 2). Statistical differences between the widths of the tree rings containing IADFs and the widths of tree rings without IADFs were found in 23 of the 35 analysed sites $(\mathrm{p}<0.05)$. Higher differences were observed for the Balearic sites (Island of Mallorca) and coastal areas. For 12 of the sites analysed, mainly inland, no differences in tree ring widths were found (Fig. 9).

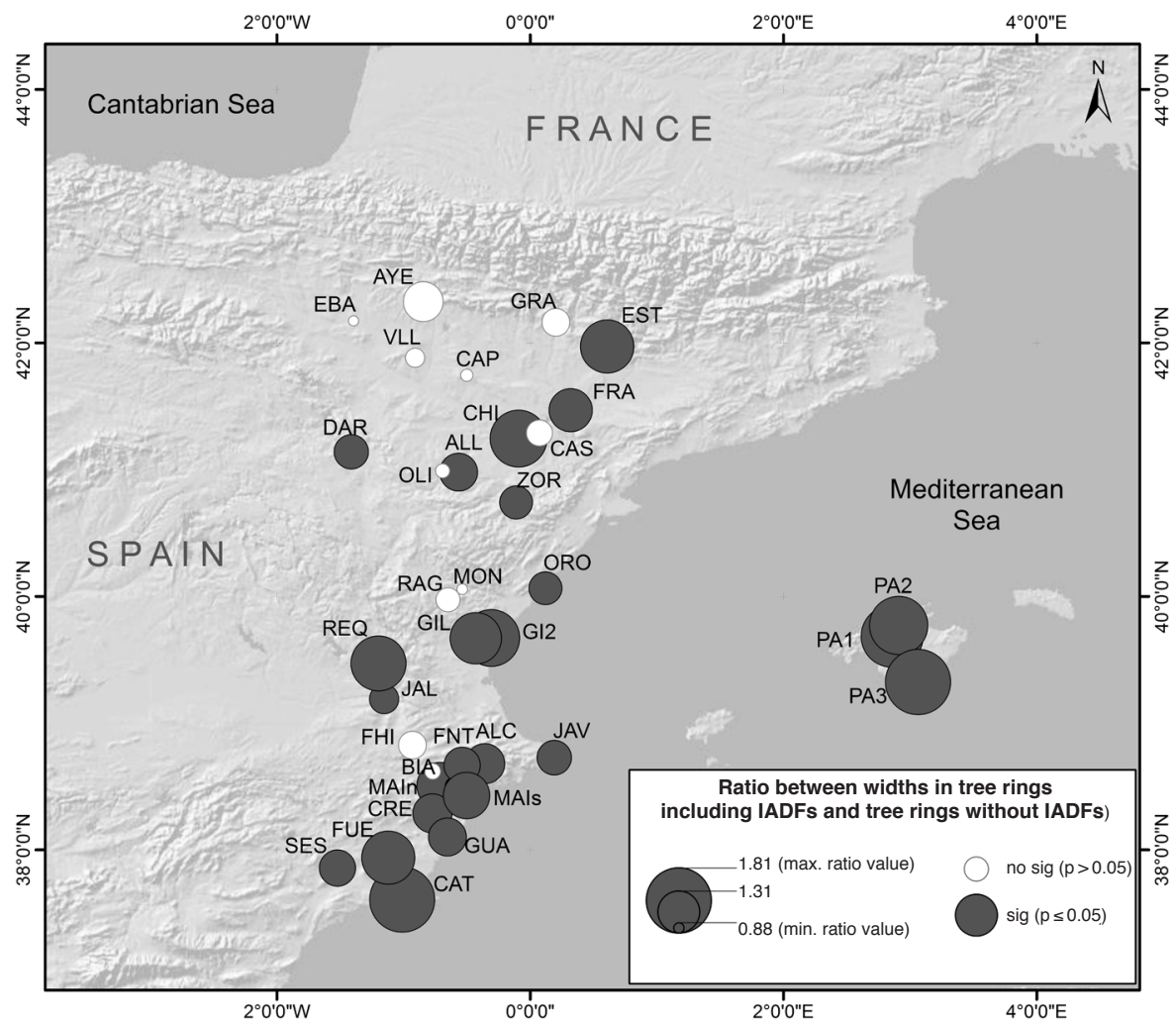

Figure 9. Mean ratio between the widths of tree rings containig IADFs and the widths of tree rings without IADFs on 35 sites. The circles marked in dark gray indicate the sites where the tree rings containing IADFs are significantly wider than the tree rings without IADFs. The white circles represent the sites without significant differences between the width of tree rings with and without IADFs. 


\section{DISCUSSION}

The study of anatomical features of wood represents a promising approach for a better interpretation of the influence of seasonal climate on tree rings (Fonti et al. 2010; von Arx et al. 2013; Wegner et al. 2013). IADFs in tree rings can be used as a key intraannual feature, because of their relation to climatic variability and change, and their occurrence in numerous species growing in different environmental conditions, e.g. Pinus halepensis (De Luis et al. 2011a; Olivar et al. 2012), Pinus pinea (Campelo et al. 2007a), Pinus pinaster (De Micco et al. 2007; Vieira et al. 2009; Rozas et al. 2011; Campelo et al.2013), Arbutus unedo (Battipaglia et al. 2010, 2013; De Micco et al. 2012), Quercus ilex (Campelo et al. 2007b), Juniperus virginiana (Edmondson 2010), Pinus banksiana (Copenheaver et al. 2006; Hoffer \& Tardif 2009), Pinus sylvestris (Rigling et al. 2001; Panayotov et al. 2013), Pinus elliottii var. densa (Harley et al.2012), Picea abies (Zubizarreta-Gerendiain et al.2012), or Pseudotsuga menziesii (Martinez-Meier et al. 2008).

In addition, the climatic information that can be obtained from IADFs is complementary to the climatic signals obtained from tree-ring widths (Novak et al. 2013), and the occurrence of IADFs is connected with intra-annual dynamics of wood formation (De Luis et al. 2007, 2011b).

The study of IADFs in wood has a great potential, but there are still problems in their analysis. First, different studies use different classifications for IADFs (E-rings, L-rings, early-IADF, mid-IADF, late-IADF), depending on the position of IADFs within the tree ring. The type and position of IADF is normally visually determined by examining the tree rings under a stereomicroscope, and IADFs are dated and assigned to earlywood or latewood subjectively (Rigling et al. 2001; Campelo et al. 2007a; Battipaglia et al. 2010; De Micco et al. 2012). In our previous research of P. halepensis growing in contrasted environmental conditions, we found that a pre-cise classification of IADFs, despite being subjective, can be performed (Novak et al.2013).

However, at transitional sites which were included in the present study, such classification is even more subjective. This is the main reason that in this study of trees from a great variety of sites we adopted a more conservative approach of just classifying the presence or absence of IADFs in the tree rings.

In addition, IADF frequencies (as well as other biological parameters like tree-ring widths) are known to be age/size dependent, which has been previously demonstrated by comparing the frequencies in the trees of different ages/sizes (De Luis et al. 2009; Vieira et al. 2009; Campelo et al.2013). However, it has yet to be established whether this relation is linear or not. In the presented dendrochronological network of P. halepensis in Spain we demonstrated that the relationship between IADF frequency and age exists. The IADF frequency, observed in samples taken at breast height, increases with cambial age for the first 27 years and then decreases. We explained the effect of the age with a three-parameter Weibull function, which proved to be a useful tool for a description of the effect of age on IADF frequency, and as a model for detrending and interpretation of the effects of climate on IADF formation. We propose to use and test this model in other species and environmental conditions. 
Our approach also shows limitations related to tree age, which was determined on the samples extracted from the trees at breast height, and does not represent exact tree age. It is difficult to resolve this problem, because the majority of dendrochronological studies are based on samples extracted at breast height. In future studies it would be interesting to contrast different effects, like tree height, tree size, and age, to improve the Weibull model as a detrending tool.

Comparison of IADF frequency and climatic influences across the distribution of the species is difficult due to differences in population structure (age). In this context, the Weibull detrending model, as a common procedure used across the network, represents an important advance in making the sites comparable. Our study demonstrated that IADF frequency varies across the geographical distribution of P. halepensis, and that the occurrence of IADFs is distributed across a clear geographical/environmental gradient. IADFs are more frequent at sites and in the years with warm climatic conditions, and where/when autumn is the main precipitation season (mainly at coastal sites). In contrast, in colder and dryer conditions in autumn, IADFs are scarce (inland or on high elevated sites).

The studies relating IADFs and climate are mainly based on information from local sites and there are few studies reporting how climatic influences vary across environmental gradients (Campelo et al. 2007a; Battipaglia et al. 2010; Olivar et al. 2012; Cherubini et al. 2013; Mamet \& Kershaw 2013; Novak et al. 2013). In the current study we used combined spatial and temporal variations in IADF frequency across a wide geographical range including a wide environmental gradient in a single analysis. From the statistical point of view, the methodology is quite simple and we propose that it should be tested in other species and/or environmental conditions. In our analysis we found, contrary to expectations and variations described for other species, that summer conditions (especially maximal and minimal temperatures, as well as precipitation) did not explain spatial and temporal variations of IADF frequency (Copenheaver et al. 2010; Olivar et al. 2012; Zubizarreta-Gerendiain et al. 2012; Campelo et al. 2013). Our results are partly in agreement with the results of Vieira et al. (2010) who found that IADF frequency in latewood of Pinus pinaster was positively related to autumn precipitation, and with Campelo et al. (2007a), who observed the same in Pinus pinea. It should also be noted that $P$. halepensis in Spain predominately shows L-type IADFs with earlywood-like cells in latewood which are formed after reactivation of cambium in autumn (De Luis et al. 2011b; Novak et al. 2013).

In our study, occurrence of IADFs proved to be related to suitable conditions for growth in autumn with mild temperatures (mainly minimum temperatures) and suitable wetness. The results are in agreement with our previous studies, which have demonstrated that IADF frequencies in adult (De Luis et al. 2011b) and juvenile trees of P. halepensis (De Luis et al. 2011a) are related to cambial reactivation after summer. According to this interpretation, IADF frequencies are not directly related to summer stress, but to favourable conditions in autumn, which promote cambial reactivation.

Our results also demonstrate that tree rings containing IADFs are wider than those without IADFs. This is in line with the former interpretation since the reactivation in 
autumn permits the trees to complete a second period of radial growth. Campelo et al (2013) and Copenheaver et al. (2006) also report that tree rings with IADFs are wider, which suggests that IADF formation is related to favourable growing conditions. In contrast, Bogino and Bravo (2009) have shown radial growth of Pinus pinaster subsp. mesogeensis to be negatively correlated with the presence of IADFs. A possible explanation could be that $P$. halepensis is an extraordinarily plastic species, able of reactivation after summer if the conditions are favourable. Other species perhaps do not have such a plastic character and thus no reactivation. In addition, the predominant environmental conditions in our study areas (Western Mediterranean) are quite special within the Mediterranean area, and are characterised by regularly abundant autumn precipitation. It should be interesting to explore whether P. halepensis growing in the Eastern Mediterranean, where the precipitation is mainly restricted to winter, also presents the same growth pattern, a similar frequency of IADFs in the wood and a similar response to climatic factors promoting their formation.

\section{CONCLUSIONS}

IADF frequency in Pinus halepensis proved to be age dependent and showed an asymmetric bell-shaped distribution with its maximum at the cambial age of 27 years at breast height.

The effect of age on IADF frequency can be explained with a three-parameter Weibull function, which proved to be a useful tool, both for description as well as a model for detrending and interpretation of the effects of climate on IADF formation.

IADF frequency varies across the geographical distribution of $P$. halepensis, with a clear geographical/environmental gradient. IADFs are more frequent at the sites and in the years with warm climatic conditions, and where/when autumn is the main precipitation season (coastal sites). In contrast, under colder and dryer conditions in autumn, the presence of IADFs is scarce (inland or high elevated sites).

Spatio-temporal analysis revealed that IADF formation is strongly related to warm conditions (especially with minimum temperatures) in summer, dry conditions in late spring and summer, and wet conditions in late summer and autumn. This indicates that IADF formation is not related to stressful conditions during summer, but to favourable conditions during autumn which promote cambial reactivation.

These results suggest that IADF formation indicates plasticity of P. halepensis and its ability to resume cambial activity after summer drought.

Our results also show that tree rings containing IADFs are wider than those without IADFs, suggesting that IADF formation is not related to stressful but rather to favourable climatic conditions.

\section{ACKNOWLEDGEMENTS}

This work was supported by the Spanish Ministry of Science and Innovation (MICINN), the ELENA program (CGL2012-31668) and by the FEDER program of the European Union. The cooperation among international partners was supported by the COST Action FP1106, STReESS. We thank three anonymous reviewers and Luka Rejc for improving the English language of this manuscript. 


\section{REFERENCES}

Alcamo J, Moreno JM, Nováky B, Bindi M, Corobov R, et al. 2007. Europe. In: Parry ML, Canziani OF, Palutikof JP, van der Linden PJ, Hanson CE, et al. (eds.), Climate Change 2007: Impacts, Adaptation and Vulnerability. Contribution of Working Group II to the Fourth Assessment Report of the Intergovernmental Panel on Climate Change: 541-580. Cambridge University Press, Cambridge, UK.

Baillie MGL \& Pilcher JR. 1973. A simple cross-dating program for tree-ring research. TreeRing Bull. 33: 7-14.

Barbéro M, Loisel R, Quezel P, Richardson MD \& Romane F. 1998. Pines of the Mediterranean basin. In: Richardson DM (ed.), Ecology and biogeography of Pinus: 153-170. Cambridge University Press, Cambridge.

Battipaglia G, De Micco V, Brand WA, Linke P, Aronne G, Saurer M \& Cherubini P. 2010. Variations of vessel diameter and ${ }^{13} \mathrm{C}$ in false rings of Arbutus unedo L. reflect different environmental conditions. New Phytol. 188: 1099-1112.

Battipaglia G, Saurer M, Cherubini P, Calfapietra C, McCarthy HR, Norby RJ \& Cotrufo MF. 2013. Elevated $\mathrm{CO}_{2}$ increases tree-level intrinsic water use efficiency: insights from carbon and oxygen isotope analyses in tree rings across three forest FACE sites. New Phytol. 197: $544-554$

Bogino S \& Bravo F. 2009. Climate and intra-annual density fluctuations in Pinus pinaster subsp. mesogeensis in Spanish woodlands. Can. J. For. Res. 39: 1557-1565.

Briffa K, Jones PD, Bartholin TS, Eckstein D, Schweingruber FH, Karlén W, Zetterberg P \& Eronen M. 1992. Fennoscandian summers from ad 500: temperature changes on short and long timescales. Clim. Dyna. 7: 111-119.

Campelo F, Gutierrez E, Ribas M, Nabais C \& Freitas H. 2007b. Relationship between climate and double rings in Quercus ilex from northeast Spain. Can. J. For. Res. 37: 1915-1923.

Campelo F, Nabais C, Freitas H \& Gutierrez E. 2007a. Climatic significance of tree-ring width and intra-annual density fluctuations in Pinus pinea from a dry Mediterranean area in Portugal. Ann. For. Sci. 64: 229-238.

Campelo F, Vieira J \& Nabais C. 2013. Tree-ring growth and intra-annual density fluctuations of Pinus pinaster responses to climate: does size matter? Trees 27: 763-772.

Cherubini P, Humbel T, Beeckman H, Gärtner H, Mannes D, et al. 2013. Olive tree-ring problematic dating: a comparative analysis on Santorini (Greece). PLoS ONE 8: e54730. doi:10.1371/journal.pone.0054730.

Christensen JH, Hewitson B, Busuioc A, Chen A, Gao X, et al. 2007. Regional climate projections. In: Solomon S, Qin D, Manning M, Chen Z, Marquis M, et al. (eds.), Climate Change 2007: The physical science basis. Contribution of Working group I to the Fourth Assessment Report of the Intergovernmental Panel on Climate Change: 847-940. Cambridge University Press, Cambridge, UK and New York, USA.

Copenheaver CA, Gärtner H, Shäffer I, Vaccari FP \& Cherubini P. 2010. Drought-triggered false ring formation in Mediterranean shrubs. Botany 88: 545-555.

Copenheaver CA, Pokorski EA, Currie JE \& Abrams MD. 2006. Causation of false ring formation in Pinus banksiana: a comparison of age, canopy class, climate, and growth rate. For. Ecol. Manag. 236: 348-355.

De Luis M, Gričar J, Čufar K \& Raventós J. 2007. Seasonal dynamics of wood formation in Pinus halepensis from dry and semi-arid ecosystems in Spain. IAWA J. 28: 389-404.

De Luis M, Novak K, Čufar K \& Raventós, J. 2009. Size mediated climate-growth relationships in Pinus halepensis and Pinus pinea. Trees 23: 1065-1073.

De Luis M, Novak K, Raventós J, Gričar J, Prislan P \& Čufar K. 2011a. Cambial activity, wood formation and sapling survival of Pinus halepensis exposed to different irrigation regimes. For. Ecol. Manag. 262: 1630-1638. 
De Luis M, Novak K, Raventós J, Gričar J, Prislan P \& Čufar K. 2011b. Climate factors promoting intra-annual density fluctuations in Aleppo pine (Pinus halepensis) from semiarid sites. Dendrochronologia 29: 163-169.

De Micco V, Battipaglia G, Brand W, Linke P, Saurer M, Aronne G \& Cherubini P. 2012. Discrete versus continuous analysis of anatomical and $\delta^{13} \mathrm{C}$ variability in tree rings with intraannual density fluctuations. Trees 26: 513-524.

De Micco V, Saurer M, Aronne G, Tognetti R \& Cherubini P. 2007. Variations of wood anatomy and $\delta^{13} \mathrm{C}$ within-tree rings of coastal Pinus pinaster showing intra-annual density fluctuations. IAWA J. 28: 61-74.

De Micco V, Zalloni E, Balzano A \& Battipaglia G. 2013. Fire influence on Pinus halepensis: wood responses close and far from scar. IAWA J. 34: 446-458.

Edmondson JR. 2010. The meteorological significance of false rings in eastern red cedar (Juniperus virginiana L.) from the southern great plains, U.S.A. Tree-ring Research 66: 19-33.

Esper J, Cook ER, Krusic PJ, Peters K \& Schweingruber FH. 2003. Tests of the RCS method for preserving low-frequency variability in long tree-ring chronologies. Tree-ring Research 59: 81-98.

Fonti P, von Arx G, García-González I, Eilmann B, Sass-Klaassen U, Gärtner H \& Eckstein D. 2010. Studying global change through investigation of the plastic responses of xylem anatomy in tree rings. New Phytol. 185: 42-53.

Girard F, Vennetier M, Guibal F, Corona C, Ouarmim S \& Herrero A. 2012. Pinus halepensis Mill. crown development and fruiting declined with repeated drought in Mediterranean France. Europ. J. For. Res. 131: 919-931.

Harley GL, Grission-Mayer HD, Franklin JA, Anderson C \& Kose N. 2012. Cambial activity of Pinus elliottii var. densa reveals influence of seasonal insolation on growth dynamics in the Florida Keys. Trees 26: 1449-1459.

Herrera S, Gutiérrez JM, Ancel R, Pons MR, Frías MD \& Fernández J. 2012. Development and analysis of a 50 year high-resolution daily gridded precipitation dataset over Spain (Spain02). Int. J. Climatol. 32: 74-85.

Hoffer M \& Tardif J. 2009. False rings in jack pine and black spruce trees from eastern Manitoba as indicators of dry summers. Can. J. For. Res. 39: 1722-1736.

Holmes R. 1994. Dendrochronology program library user's manual. Laboratory of Tree-Ring Research, University of Arizona, Tucson, USA.

Mamet SD \& Kershaw GP. 2013. Age-dependency, climate, and environmental controls of recent tree-growth trends at subarctic and alpine treelines. Dendrochronologia 31: 75-87.

Martin-Benito D, Beeckman H \& Canellas I. 2013. Influence of drought on tree rings and tracheid features of Pinus nigra and Pinus sylvestris in a mesic Mediterranean forest. Europ. J. For. Res. 132: 33-45.

Martinez-Meier A, Sanchez L, Pastorino M. Gallo L \& Rozenberg P. 2008. What is hot in tree rings? The wood density of surviving Douglas-firs to the 2003 drought and heat wave. For. Ecol. Manag. 256: 837-843

Nicault A, Alleaume S, Brewer S, Carrer M, Nola P \& Guiot J. 2008. Mediterranean drought fluctuation during the last 500 years based on tree-ring data. Clim. Dyna. 31: 227-245.

Novak K, De Luis M, Čufar K \& Raventós J. 2011. Frequency and variability of missing tree rings along the stems of Pinus halepensis and Pinus pinea from a semiarid site in SE Spain. J. Arid Environm. 75: 494-498.

Novak K, De Luis M, Raventos J \& Čufar K. 2013. Climatic signals in tree-ring widths and wood structure of Pinus halepensis in contrasted environmental conditions. Trees: 27: 927-936.

Olivar J, Bogino S, Spiecker H \& Bravo F. 2012. Climate impact on growth dynamics and intra-annual density fluctuations in Aleppo pine (Pinus halepensis) tree on different crown classes. Dendrochronologia 30: 35-47. 
Panayotov M, Zafirov N \& Cherubini P. 2013. Fingerprints of extreme climate events in Pinus sylvestris tree rings from Bulgaria. Trees 27: 211-227.

Richardson DM \& Rundel PW. 1998. Ecology and biogeography of Pinus: an introduction. In: Richardson DM (ed.), Ecology and biogeography of Pinus: 3-46. Cambridge University Press, Cambridge, UK.

Rigling A, Waldner PO, Forster T, Bräker O \& Pouttu A. 2001. Ecological interpretation of treering width and intraannual density fluctuations in Pinus sylvestris on dry sites in the central Alps and Siberia. Can. J. For. Res. 31: 18-31.

Rozas V, García-González I \& Zas R. 2011. Climatic control of intra-annual wood density fluctuations of Pinus pinaster in NW Spain. Trees 25: 443-453.

Schweingruber FH. 1988. Tree rings, basics and application of dendrochronology. Kluwer Academic Publishers, Dordrecht, Boston, London.

Vieira J, Campelo F \& Nabais C. 2009. Age-dependent responses of tree-ring growth and intraannual density fluctuations of Pinus pinaster to Mediterranean climate. Trees 23: 257-265.

Vieira J, Campelo F \& Nabais C. 2010. Intra-annual density fluctuations of Pinus pinaster are a record of climatic changes in the western Mediterranean region. Can. J. For. Res. 40: $1567-1575$.

von Arx G, Kueffer C \& Fonti P. 2013. Quantifying plasticity in vessel grouping - added value from the image analysis tool ROXAS. IAWA J. 34: 433-445.

Wegner L, von Arx G, Sass-Klaassen U \& Eilmann B. 2013. ROXAS - an efficient and accurate tool to detect vessels in diffuse-porous species. IAWA J. 34: 425-432.

Zubizarreta-Gerendiain A, Gort-Oromi J, Mehtätalo L, Peltola H, Venäläinen A \& Pulkkinen P. 2012. Effects of cambial age, clone and climatic factors on ring width and ring density in Norway spruce (Picea abies) in southeastern Finland. For. Ecol. Manag. 263: 9-16.

Accepted: 3 September 2013 